Check for updates

Cite this: RSC Adv., 2018, 8, 42170

\title{
Hair growth promotion effect of cedrol cream and its dermatopharmacokinetics
}

\author{
Yan Zhang, ${ }^{a}$ Jie-wen Wang, ${ }^{a}$ Fan-zhi Qu, ${ }^{a}$ Yu-meng Zhang, ${ }^{a}$ Guang-yue Su*ab \\ and Yu-qing Zhao (DD *ab
}

Topical use of cedrol ethanol has been reported to have a beneficial effect on hair loss. However, the use of cedrol has been limited by application-related issues, such as poor water solubility and volatile features. Therefore, the present study developed a cream formulation of cedrol and evaluated various physicochemical parameters of the prepared cream. The optimized cedrol cream was selected after orthogonal tests and determined further. The dermatopharmacokinetics were studied to investigate the absorption difference between cedrol cream and cedrol ethanol after dermal application, and the concentrations of cedrol in skin were analysed by the gas chromatography-mass spectrometry (GC-MS) method. By comparison, the area under the curve $\left(\mathrm{AUC}_{0-24 \mathrm{~h}}\right)$ of cedrol cream was almost three times higher than that of cedrol ethanol. Moreover, this study was undertaken to evaluate the hair growth promoting efficacy of cedrol cream in C57BL/6 mice and Wistar rats. Macroscopic assessment and alopecia score showed that C57BL/6 mice treated with cedrol cream showed a faster production of pigmentation and a higher score at different growth stages than other groups. The hair length of the cedrol cream-treated group was much longer than those of the cedrol ethanol and minoxidil groups. Histological analyses indicated that in the cedrol ethanol group, most follicles of the C57BL/6 mice were in the catagen phase, whereas nearly $83 \%$ of hair follicles in the cedrol cream group remained in the anagen phase. Taken together, our data strongly suggest that the cream formulation of cedrol has a stronger hair growth promotion effect, gave no irritation and was safe for topical administration.

Received 19th October 2018

Accepted 18th November 2018

DOI: $10.1039 / c 8 r a 08667 b$

rsc.li/rsc-advances with a high boiling point (molecular weight, 222.37), which has been reported to have antispasmodic, sedative, anti-cancer, antifungal, analgesic and anti-inflammatory effects. ${ }^{13-18}$ Its safety for topical administration has been confirmed. ${ }^{19,20}$ Our previous studies demonstrated that topically applied cedrol (dissolved in $85 \%$ ethanol) could effectively promote hair growth and prevent chemotherapy-induced alopecia by stimulating hair regeneration and prolonging the anagen phase of hair follicles. ${ }^{21,22}$ However, long-term use of high concentrations of ethanol may lead to many skin problems, including dandruff, dry skin and allergies. Cedrol also exhibits a series of application-related issues, such as poor water solubility $\left(21.88 \mathrm{mg} \mathrm{l}^{-1}, 25^{\circ} \mathrm{C}\right)$, volatile features and lipophilicity $\left(\log K_{\mathrm{ow}}\right.$ 4.67). ${ }^{23}$ As mentioned above, it is necessary to develop a new alternative topical formulation of cedrol to overcome these disadvantages.

In the present study, with an aim to increase the skin retention and dermal bioavailability of cedrol, the cream formulations were designed according to an orthogonal experiment. The skin retention of cedrol cream and cedrol ethanol in vivo was also evaluated by GC-MS method. A skin irritation test was also carried out. Furthermore, the hair growth-promoting activities of cedrol cream were investigated in mice and rats.
${ }^{a}$ Shenyang Pharmaceutical University, No. 103, Wenhua Road, Shenyang 110016, People's Republic of China. E-mail: zyq4885@126.com; suggyy@163.com; Fax: +86 24 43520300; Tel: +862443520309

${ }^{b}$ Key Laboratory of Structure-based Drug Design and Discovery of Ministry of Education, Shenyang Pharmaceutical University, Shenyang 110016, China 
$\mathbf{a}$

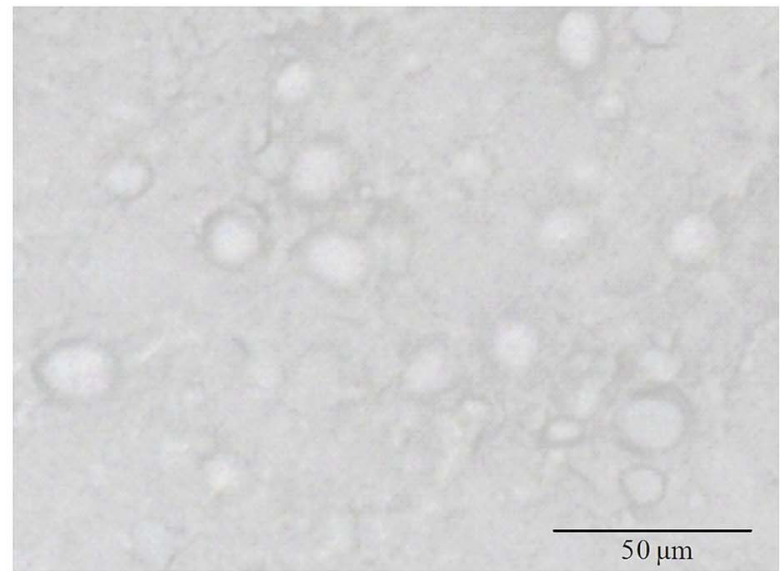

b A

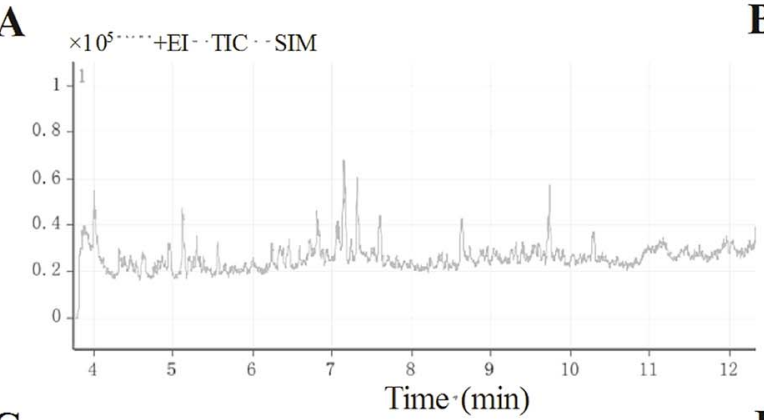

C

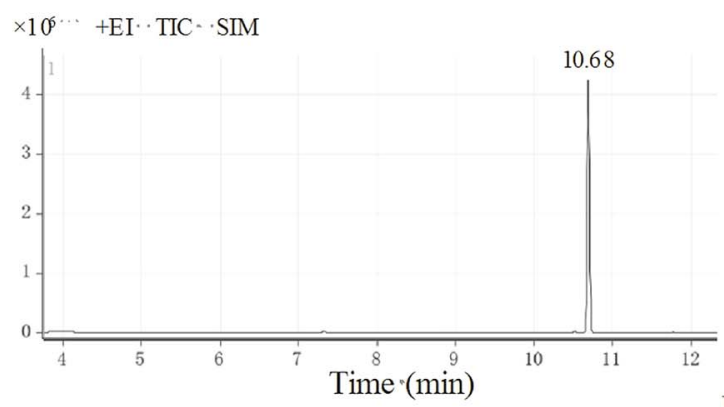

$\mathbf{E}$

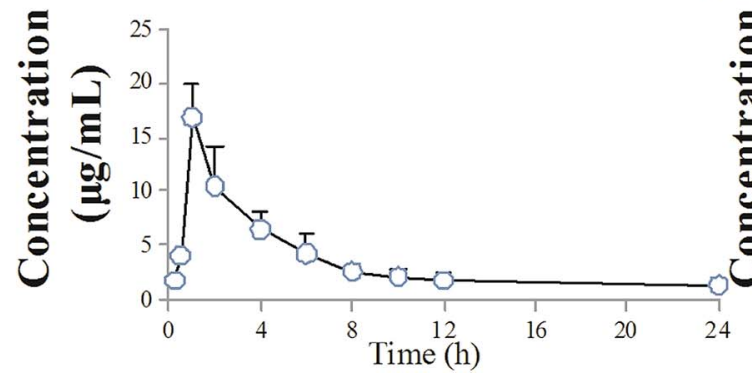

B

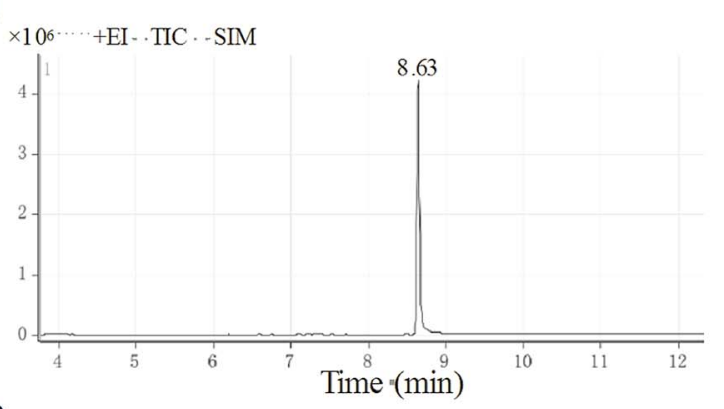

D
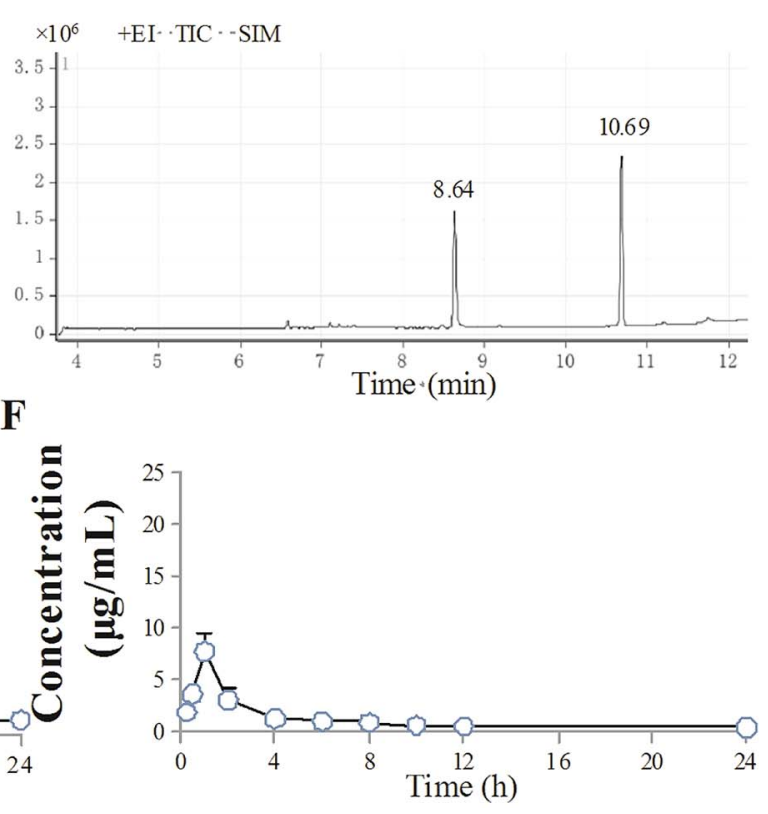

Fig. 1 (a) Micrograph of cedrol cream. (b) Chromatograms and mean mice skin tissue concentration-time profiles. Typical chromatograms for (A) drug-free skin tissue, (B) skin tissue spiked with cedrol, (C) skin tissue spiked with IS, (D) a skin tissue sample $2 \mathrm{~h}$ after topical administration to a mouse. Drug retention in mice skin at various time intervals after single topical application of (E) cedrol cream and (F) cedrol ethanol at 100 mg $\mathrm{kg}^{-1}$. 


\section{Experiment}

\subsection{Materials}

Minoxidil was purchased from a local market and used as a positive control. Liquid paraffin, stearic acid and monostearate glyceride were purchased from Xinxing (Tieling) Pharmaceutical Co., Ltd, China. Tween 80 and glycerin were purchased from China Pharmaceutical Group Chemical Reagent Co., Ltd, China. White Vaseline was purchased from Tianjin Hengxing Chemical Reagent Co., Ltd, China.

\subsection{Animals}

Mice (Animal License no. SCXK (Liao) 2015-0001) were obtained from The Laboratory Animal Center of Shenyang Pharmaceutical University (Shenyang, PR China). Female KM mice aged 5-6 weeks old and weighing $20 \pm 2 \mathrm{~g}$ were employed for dermatopharmacokinetic studies. Female C57BL/6 mice and male Wistar rats, weighing $20 \pm 2 \mathrm{~g}$ and $140 \pm 10 \mathrm{~g}$, respectively, were employed for evaluating the hair-growth promoting effects. Mice were housed in cages and allowed to acclimatize for a minimum of 7 days before initiating the experiment. All the animals were kept at ambient temperature with a $12 \mathrm{~h}$ night/day cycle, and supplied with a standard pellet diet and water. This study was performed in strict accordance with the Guidelines for the Care and Use of Laboratory Animals of Shenyang Pharmaceutical University, and approved by the Institutional Animal Ethics Committee (approval protocol number: SYPU-IACUC-C2018-3-23-104; Liaoning, China).

\subsection{Development of cedrol cream}

2.3.1. Orthogonal experiment. The cedrol formula was screened from several classic prescriptions and prepared based on an orthogonal experiment design $\mathrm{L}_{9}\left(3^{4}\right)$. Through the single factor experiment results, the following four factors were analyzed: the concentrations of Tween 80, white Vaseline, liquid paraffin and glyceryl monostearate, which had a remarkable influence on the quality of the cream produced. Different batches of cedrol cream were measured for organoleptic properties like appearance, odour, malleability, centrifugal stability, and heat- and cold-resistant stability. The particle size of the cream was measured by a Nikon optical microscope.

2.3.2. Preparation of cedrol cream. The water bath was heated until the water phase (glycerine, Tween 80 and deionized water) dissolved and the temperature was maintained at $80{ }^{\circ} \mathrm{C}$. Glyceryl monostearate, liquid paraffin, white Vaseline and stearic acid were blended under gentle stirring in water bath at $80{ }^{\circ} \mathrm{C}$ to form the oil phase. Successively, cedrol was added in the oil phase until completely dissolved. The oil phase was added to the water phase dropwise with magnetic agitation (400 $\mathrm{rpm}$ ). After being emulsified for $30 \mathrm{~min}$, the cream was allowed to cool naturally to room temperature.

\subsection{Dermatopharmacokinetics}

2.4.1. Chromatography and mass spectrometry conditions. Chromatographic separation was performed by using a $7890 \mathrm{~B}$ gas chromatographic system combined with a 7000 triple quadrupole mass spectrometer (GC-MS, Agilent, CA, USA). Chromatographic separation was achieved on a HP-5MS column $(30 \mathrm{~m} \times 0.25 \mathrm{~mm} \times 0.25 \mu \mathrm{m})$ purchased from America.

Cedrol was analysed by GC-MS using nitrogen as the carrier gas with a flow of $1.0 \mathrm{ml} \mathrm{min}{ }^{-1}$. The initial column temperature was held at 110 for $2 \mathrm{~min}$ and then increased at a rate of $15^{\circ} \mathrm{C} \mathrm{min}{ }^{-1}$ to $180{ }^{\circ} \mathrm{C}$ for $2 \mathrm{~min}$ and then increased at a rate of $10{ }^{\circ} \mathrm{C} \mathrm{min}^{-1}$ to $240{ }^{\circ} \mathrm{C}$ for a further $2 \mathrm{~min}$. The mass spectrometer was operated in positive electron impact ionization mode $(70 \mathrm{eV})$. The MS interface and ion source temperatures were set at $280{ }^{\circ} \mathrm{C}$ and $230{ }^{\circ} \mathrm{C}$, respectively. The quantification was performed using selected ion detection (SIM): $\mathrm{m} / \mathrm{z} 150$ and 207 for cedrol, $m / z 119$ for IS.

2.4.2. Application to pharmacokinetic study. The tests were performed using KM mice $(n=5)$. The day before the experiment, an area of $2 \mathrm{~cm} \times 2 \mathrm{~cm}$ was removed from the dorsal skin of the mice. The animals were divided into two groups: A and B, which were treated with the cedrol ethanol and cedrol cream, respectively. Cedrol ethanol and the optimized cedrol cream (100 $\mathrm{mg} \mathrm{kg}^{-1}$ ) were applied on the dorsal prepared region of the animals. The selected mice were fixed, without anesthesia. Mice were sacrificed at different time points: $0.25 \mathrm{~h}, 0.5 \mathrm{~h}, 1 \mathrm{~h}, 2 \mathrm{~h}, 4 \mathrm{~h}, 6 \mathrm{~h}, 8 \mathrm{~h}, 10 \mathrm{~h}, 12 \mathrm{~h}$, and $24 \mathrm{~h}$. The remaining formulation was removed by a cotton swab impregnated with physiological saline. The stratum corneum, subcutaneous fat and connective tissue of the skin samples were removed with adhesive tape and surgical shears. ${ }^{24}$ Mice skin was collected and the bio-samples were stored at $-20{ }^{\circ} \mathrm{C}$ until analysis.

Each sample was homogenized with $1.0 \mathrm{ml}$ of saline with IS, then $1.0 \mathrm{ml}$ of $n$-hexane was added and vortex mixed for $3 \mathrm{~min}$. The samples were ultrasonicated for $5 \mathrm{~min}$ and centrifuged at $14000 \mathrm{rpm}$ for $5 \mathrm{~min}$. $1.0 \mu \mathrm{l}$ of supernatant was injected for GC-MS analysis.

Pharmacokinetic parameters were calculated by noncompartmental method using the pharmacokinetic program DAS 2.0. The maximum concentration $\left(C_{\max }\right)$, maximum drug concentration time $\left(T_{\max }\right)$, elimination half-life $\left(T_{1 / 2}\right)$, mean residence time (MRT) and area under the curve $\left(\mathrm{AUC}_{0-24} \mathrm{~h}\right)$ were calculated.

\subsection{Hair-growth studies}

C57BL/6 mice $(n=10)$ and Wistar mice $(n=6)$ were randomly divided into four groups. The test drugs for $\mathrm{C} 57 \mathrm{BL} / 6$ mice were cedrol ethanol $\left(20 \mathrm{mg} \mathrm{ml}^{-1}, 100 \mu \mathrm{l}\right)$, cedrol cream (5\% w/w, 0.04 g), $2 \%$ minoxidil and vehicle control. $2 \%$ minoxidil was used as the positive control. A double dosage of drugs was given to Wistar rats. The dorsal skin of C57BL/6 mice $(2 \mathrm{~cm} \times 3 \mathrm{~cm})$ and Wistar mice $(3 \mathrm{~cm} \times 3 \mathrm{~cm})$ in the telogen phase was shaved $24 \mathrm{~h}$ before the experiment. The drug/vehicle was topically administered once a day to the mice and rats on the test area, for 21 $\mathrm{d}$ and $30 \mathrm{~d}$, respectively. The hair regrowth activities of different groups were evaluated by hair growth condition, new hair length and quantitative histomorphometry. ${ }^{\mathbf{8}, \mathbf{9}}$ 


\subsection{Statistical analysis}

Values are expressed as mean \pm standard deviation (S.D.). Statistical analyses were performed using Student's $t$-test (SPSS for Windows, version 16) to determine significant differences between treatments; a $P$ value $<0.05$ was considered statistically significant.

\section{Results and discussion}

\subsection{Development of cedrol cream}

Nine different batches of oil/water $(\mathrm{O} / \mathrm{W})$ cream were prepared according to the $\mathrm{L}_{9}\left(3^{4}\right)$ matrix. The batches were scored and judged with the above-mentioned parameters for optimizing the best batch. The cream formulations were prepared by the melt emulsification method. In order to obtain a stable and high-quality cream, Tween 80 and glyceryl monostearate were chosen as the emulsifier and auxiliary emulsifier, respectively.

The results of the orthogonal experiments exhibited that the factors' levels of significance were as follows: the dosage of Tween $80>$ glyceryl monostearate > liquid paraffin $>$ white Vaseline. The intuitionistic analysis and variance analysis of the experimental results showed that the optimized cedrol formulation was $5 \%(\mathrm{w} / \mathrm{w})$ cedrol, $4 \%(\mathrm{w} / \mathrm{w})$ Tween $80,5 \%(\mathrm{w} / \mathrm{w})$ white Vaseline, $6 \%(\mathrm{w} / \mathrm{w})$ stearic acid, $10 \%(\mathrm{w} / \mathrm{w})$ glyceryl monostearate, $10 \%(\mathrm{w} / \mathrm{w})$ liquid paraffin, $11 \%(\mathrm{w} / \mathrm{w})$ glycerol and $0.2 \%$ $(\mathrm{w} / \mathrm{w})$ sorbic acid. The optimized formulation of cedrol was white in appearance with high-quality organoleptic properties and could still maintain stability under the centrifugal $(14000 \mathrm{rpm}, 1 \mathrm{~h})$, freezing $\left(-20{ }^{\circ} \mathrm{C}, 24 \mathrm{~h}\right)$ and high temperature $\left(50{ }^{\circ} \mathrm{C}, 6 \mathrm{~h}\right)$ conditions. The particle size of the cream was less than $50 \mu \mathrm{m}$ (Fig. 1a).

\subsection{Dermatopharmacokinetics}

A gas chromatographic system combined with a triple quadrupole mass spectrometer was used to determine the content of cedrol in the skin samples. The specificity of the method was demonstrated by chromatograms for cedrol and the internal standard (IS) for a drug-free skin sample, a skin sample spiked with cedrol, a skin simple spiked with IS and a skin sample from a mouse $2 \mathrm{~h}$ after topical administration (Fig. 1b). The retention times for cedrol and the IS were approximately 8.63 and $10.68 \mathrm{~min}$, respectively. No interference with other peaks was observed in the homogenate.

To assess linearity, the calibration curve was established by the plotting peak area ratio of cedrol to the IS versus the corresponding concentrations using linear regression analysis with $1 / x^{2}$ weighting. The standard equation was $y=0.283 x+0.202$ and the concentration range for cedrol in the homogenate was 0.15-40 $\mu \mathrm{g} \mathrm{ml} \mathrm{m}^{-1}$. The correlation coefficient for the standard curves was 0.9960 . The average extraction recoveries from skin samples were $79.11-83.04 \%$ for cedrol and $81.02 \%$ for the IS. The accuracy and precision were less than $15 \%$ and were acceptable.

The presented method was applied for the determination of the cedrol cream and cedrol ethanol concentrations in mice skin for $24 \mathrm{~h}$ after topic administration of a single $100 \mathrm{mg} \mathrm{kg}^{-1}$
Table 1 Pharmacokinetic parameters of cedrol cream and cedrol ethanol after topical administration of $100 \mathrm{mg} \mathrm{kg}^{-1}$ to mice ${ }^{a}$

\begin{tabular}{lccl}
\hline Parameters & Cedrol cream & Cedrol ethanol & $p$ \\
\hline $\mathrm{AUC}_{0-24 \mathrm{~h}}\left(\mu \mathrm{g} \times \mathrm{h} \mathrm{ml}^{-1}\right)$ & $82.60 \pm 22.44$ & $28.19 \pm 6.98$ & 0.001 \\
$\mathrm{AUC}_{0-\infty}\left(\mu \mathrm{g} \times \mathrm{h} \mathrm{ml}^{-1}\right)$ & $119.05 \pm 36.95$ & $33.48 \pm 10.58$ & 0.001 \\
$\mathrm{MRT}(\mathrm{h})$ & $7.12 \pm 0.29$ & $6.94 \pm 0.20$ & 0.29 \\
$T_{1 / 2}(\mathrm{~h})$ & $18.56 \pm 7.17$ & $10.03 \pm 5.14$ & 0.06 \\
$C_{\max }\left(\mu \mathrm{g} \mathrm{ml}^{-1}\right)$ & $16.83 \pm 3.15$ & $7.76 \pm 1.83$ & 0.001 \\
${ }^{a}$ The results are shown as the mean \pm standard deviation (S.D.). &
\end{tabular}

dose $(n=5)$. All main pharmacokinetic parameters were estimated by non-compartmental analysis after topical administration of cedrol cream and cedrol ethanol.

As the results show in Fig. $1 \mathrm{~b}$ and Table 1 , the mean peak concentrations of cedrol cream and cedrol ethanol were 16.83 $\mu \mathrm{g} \mathrm{ml} \mathrm{m}^{-1}$ and $7.76 \mu \mathrm{g} \mathrm{ml}{ }^{-1}$ at $1 \mathrm{~h}$ after administration, respectively. Compared with the cedrol ethanol $(10.03 \mathrm{~h})$, the $T_{1 / 2}$ of the cedrol cream $(18.56 \mathrm{~h})$ was prolonged, with an almost twofold increase. Furthermore, there were significant differences in the $\mathrm{AUC}_{0-24} \mathrm{~h}$ for cedrol cream and cedrol ethanol (82.60 $\left.\mu \mathrm{g} \mathrm{ml}^{-1} \times \mathrm{h} v s .28 .19 \mu \mathrm{g} \mathrm{ml}^{-1} \times \mathrm{h}, p<0.01\right)$. Obviously, the cedrol had better skin retention properties in the form of a cream. This may be credited to the presence of surfactants in the cream base that could contribute to the solubilization of cedrol. However, in the cedrol ethanol group, the volatilization of ethanol leads to the precipitation of cedrol.

The results also revealed that cedrol could penetrate into the skin instantaneously and the skin retention reached a peak in a short time $\left(T_{\max }, 1 \mathrm{~h}\right)$. The results in Table 1 demonstrate that cedrol cream has a longer half-life and residence time, indicating that cedrol cream can maintain a high concentration for a long time in skin, which is beneficial for the effect of the drug in the skin epidermis and dermis. Therefore, the cream was more appropriate for the topical use of cedrol.

\subsection{Effects of cedrol on hair regeneration}

Hair growth is controlled by a unique dynamic cycle comprising growth (anagen), regression (catagen) and rest (telogen) phases. ${ }^{25,26}$ Hair follicles remodel themselves repeatedly throughout adult life. ${ }^{27}$ It is generally known that the human hair cycle lasts several years; in contrast, the mouse hair cycle is only three weeks. The hair cycle in mice is similar to that of humans. Therefore, to evaluate the hair-growth conditions, C57BL/6 mice were selected and the production of pigmentation was taken as evidence during only the anagen phase. ${ }^{28,29}$

Hair growth was observed from the denuded area of C57BL/6 mice. The skin color of C57BL/6 mice in the telogen phase was pink, which darkens along with anagen initiation and then becomes grey. In comparison with the application of the control, blackened skin areas, especially in the cedrol cream group, were observed $7 \mathrm{~d}$ after shaving (Fig. 2a). At $11 \mathrm{~d}$, the cedrol cream-treated group was covered with hair in the shaved skin, whereas other groups showed relatively less hair growth. Macroscopic assessment and alopecia score (Table 2) showed that cedrol cream significantly stimulated hair growth. The 
Table 2 Hair growth-promoting scores of cedrol cream, cedrol ethanol and $2 \%$ minoxidil $^{a}$

\begin{tabular}{|c|c|c|c|c|}
\hline \multirow[b]{2}{*}{ Compounds } & \multicolumn{4}{|c|}{ The hair growth score of the mice } \\
\hline & 4 day & 6 day & 8 day & 10 day \\
\hline Control & $0.3 \pm 0.5$ & $1.0 \pm 0.7$ & $1.7 \pm 0.7$ & $2.1 \pm 0.7$ \\
\hline Cedrol ethanol & $0.5 \pm 0.5$ & $1.6 \pm 0.7$ & $2.2 \pm 0.6$ & $3.1 \pm 0.7^{* *}$ \\
\hline Cedrol cream & $0.7 \pm 0.5$ & $1.9 \pm 0.7 * *$ & $2.8 \pm 0.6^{* *}$ & $3.8 \pm 0.4^{* *}$ \\
\hline $2 \%$ minoxidil & $0.5 \pm 0.5$ & $1.7 \pm 0.5^{*}$ & $2.1 \pm 0.7$ & $3.3 \pm 0.7 * *$ \\
\hline \multicolumn{5}{|c|}{$\begin{array}{l}{ }^{a} \text { The hair-regrowth efficacies were scored according to different hair } \\
\text { growth stages. The scoring criteria were as follows: } 0 \text { points: the skin } \\
\text { of the depilatory area was pink; } 1 \text { point: the skin of the depilatory } \\
\text { area was grey; } 2 \text { points: the skin of the depilatory area was black; } 3 \\
\text { points: the hair in the depilatory area had started to grow; } 4 \text { point: the } \\
\text { short-hair growth was complete. The results are shown as the mean } \pm \\
\text { standard deviation (S.D.). }{ }^{*} P<0.05,{ }^{*} P<0.01 \text {, when compared to } \\
\text { respective control values by Student's } t \text {-test }(n=10) \text {. }\end{array}$} \\
\hline
\end{tabular}
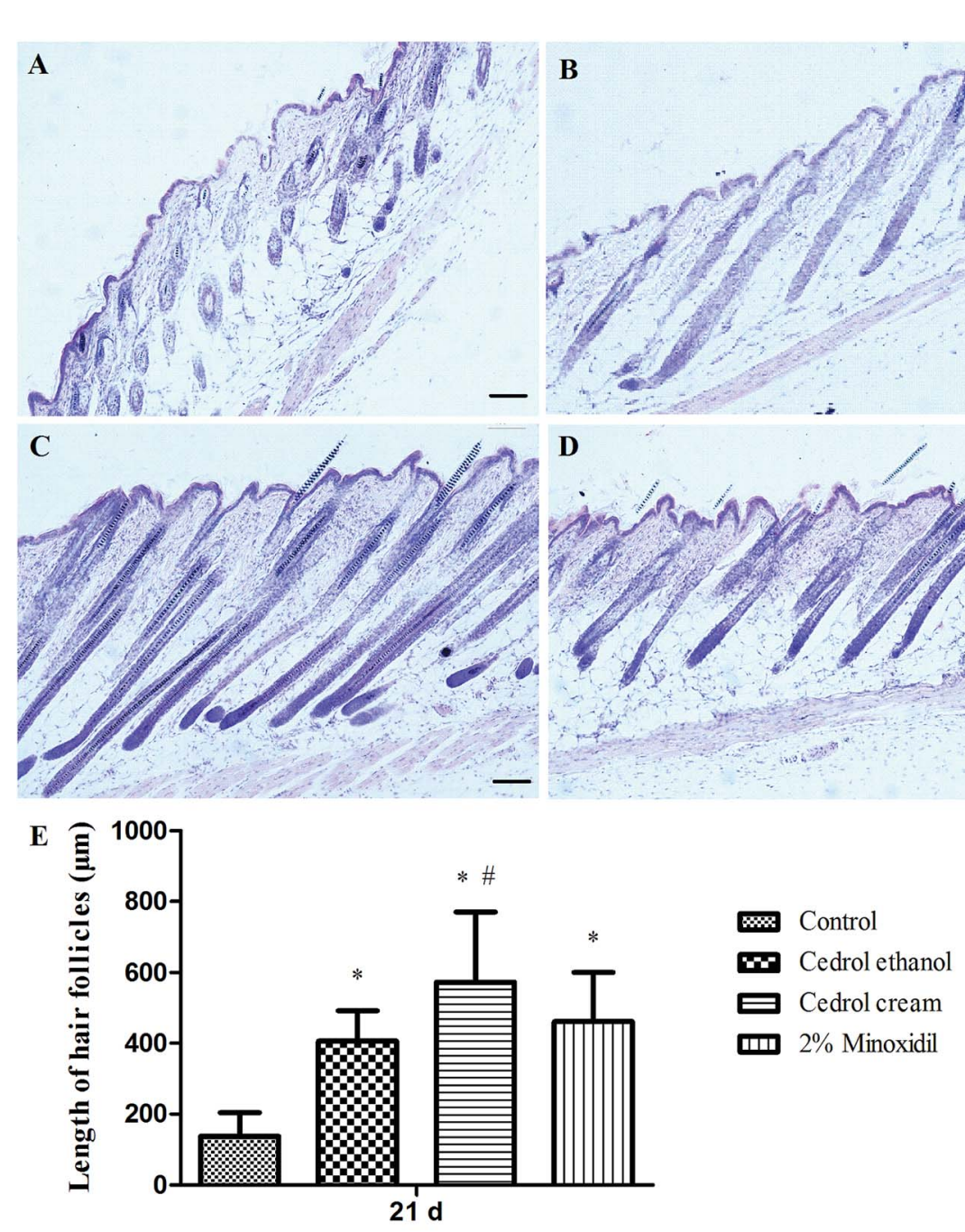

calculated. According to the data (Fig. 2b), mice treated with drugs exhibited significant activity in terms of the hair length when compared to the control group. The cedrol cream group showed the best hair growth promotion effects. Compared with the cedrol ethanol $(7.31 \mathrm{~mm})$ and minoxidil groups $(7.39 \mathrm{~mm})$, the cedrol cream group $(7.99 \mathrm{~mm})$ showed a remarkable effect on length of hair at $17 \mathrm{~d}$. At $21 \mathrm{~d}$, the hair length for the cedrol cream-treated group $(10.26 \mathrm{~mm})$ was significantly longer than that of the vehicle treated group $(8.52 \mathrm{~mm})$. The mice treated with cedrol cream exhibited significant results when compared with the cedrol ethanol group at $17 \mathrm{~d}$ and $21 \mathrm{~d}$.

To investigate the effect of the drugs on the hair follicle cyclic, hematoxylin-eosin staining was performed. In the representative longitudinal sections, the majority of hair follicles in the vehicle group were in the telogen phase, whereas nearly $83 \%$ of the hair follicles in the cedrol cream group remained in the anagen phase. In the cedrol ethanol group, most follicles were in the catagen phase with only a few in the anagen phase. However, in the mice in the minoxidil-treated

Fig. 3 Hair follicle growth in C57BL/6 mice treated with (A) control, (B) cedrol ethanol, (C) cedrol cream and (D) 2\% minoxidil. (E) The length of hair follicles in different groups were measured by an optical microscope. The results were shown as the mean \pm standard deviation (S.D.). $* P<$ 0.01 , vs. control group. ${ }^{\#} P<0.01$, vs. cedrol ethanol group $(n=10)$. 

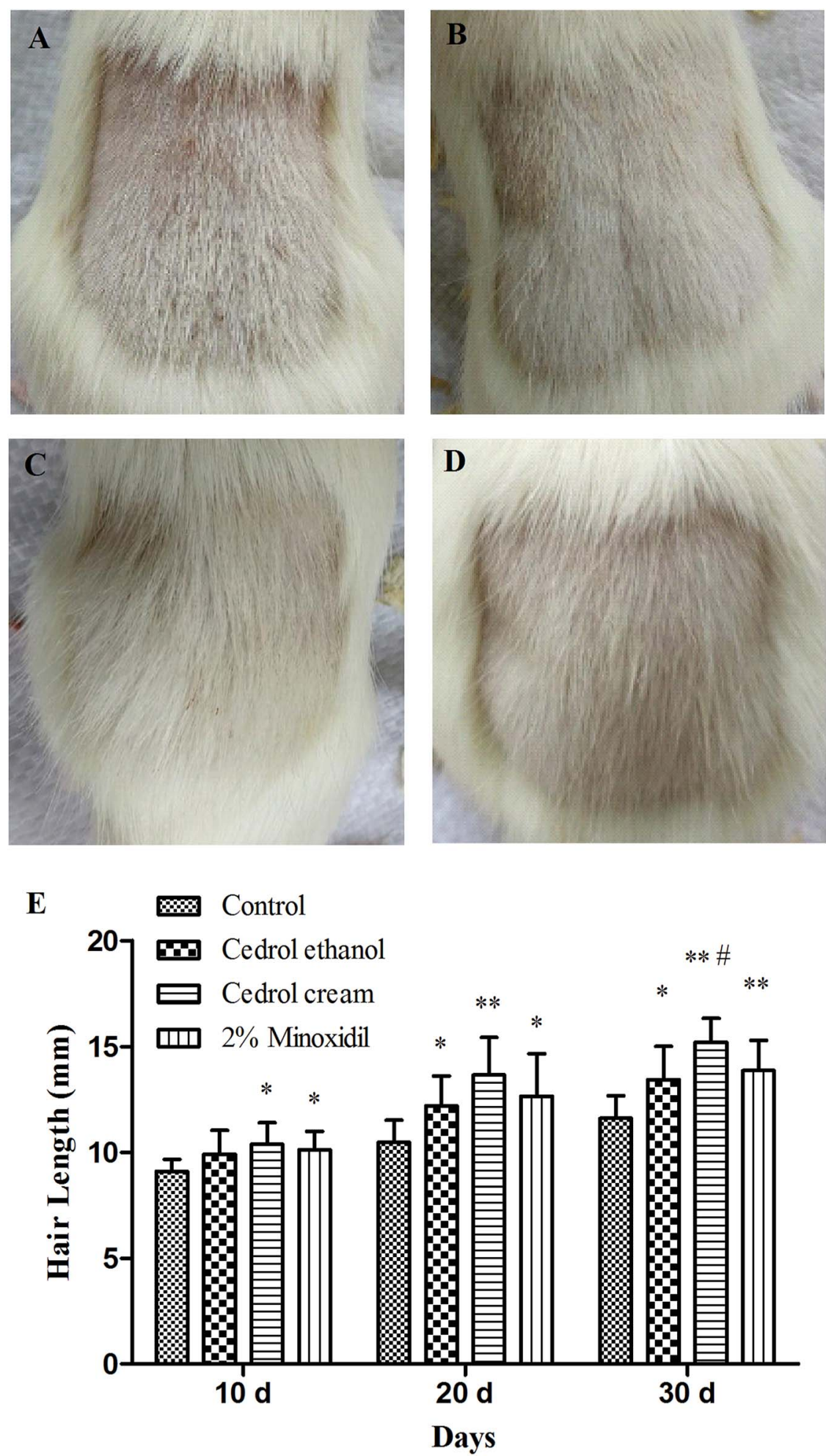

Fig. 4 Hair regrowth promoting effects of different treatments at $15 \mathrm{~d}$. Wistar rats were shaved and topically administered (A) control, (B) cedrol ethanol, (C) cedrol cream, and (D) $2 \%$ minoxidil. (E) Length of hair at different time intervals after beginning treatment. The results are shown as the mean \pm standard deviation (S.D.). ${ }^{*} P<0.05,{ }^{*} P<0.01$, vs. control group. ${ }^{*} P<0.05$, vs. cedrol ethanol group ( $n=6$ ).

group, the majority of hair follicles were in the catagen and anagen phases (Fig. 3). Histological analyses indicated that cedrol cream slowed down hair follicles into the catagen phase.
Histomorphometric analysis was performed to quantify the hair growth promoting activities. Fig. 3E showed that cedrol cream had a great influence on hair follicle length; the hair 
follicles in the cedrol cream group mice were significantly longer than for other groups. The average hair follicle length in the cedrol cream and cedrol ethanol groups were 573.28 and $406.26 \mu \mathrm{m}$ respectively. Minoxidil $(461.23 \mu \mathrm{m})$ showed approximately the same efficacy as the cedrol ethanol treated group.

To further confirm this result, we subjected Wistar rats to the same regimen for $30 \mathrm{~d}$. As shown in Fig. 4, the coverage of hair in the cedrol and minoxidil groups was significantly higher than that in the control group, and rats treated with cedrol cream were the best. In the cedrol cream group, new hair in the depilatory area was similar to that in the untreated part, while in the other three groups of rats a distinct boundary between the hair removal and the untreated areas was still observed. The effects of the cedrol ethanol were similar to those of the minoxidil. According to the data (Fig. 4E), the hair length in the cedrol and minoxidil groups was obviously superior to that of the control group. At $30 \mathrm{~d}$, the cedrol cream group (15.2 mm) showed a remarkable effect on hair length when compared to the cedrol ethanol group (13.4 $\mathrm{mm})$.

\subsection{Skin irritation study}

Wistar rats were selected to detect the irritation of cedrol cream. There was no erythema or edema of skin when cedrol cream was applied on the shaved back of rats within $72 \mathrm{~h}$. This indicated that the cream formulation of cedrol was a safe agent for topical administration.

\section{Conflicts of interest}

The authors report no conflicts of interest.

\section{Acknowledgements}

This work was supported by the Liaoning (FGW) Engineering Technology Research Center for industrial chromatographic preparation of natural innovative drugs materials (grant number 2017-1007).

\section{References}

1 D. Stough, K. Stenn, R. Haber, W. M. Parsley, J. E. Vogel, D. A. Whiting and K. Washenik, Psychological effect pathophysiology and management of androgenetic alopecia in men, Mayo Clin. Proc., 2005, 80, 1316-1322.

2 V. H. Price, Treatment of hair loss, N. Engl. J. Med., 1999, 341, 964-1773.

3 N. Hunt and S. McHale, The psychological impact of alopecia, Br. Med. J., 2005, 331, 951-953.

4 P. Myung and M. Ito, Dissecting the bulge in hair regeneration, J. Clin. Invest., 2012, 122, 448-454.

5 N. Amberg, M. Holcmann, G. Stulnig and M. Sibilia, Effects of Imiquimod on Hair Follicle Stem Cells and Hair Cycle Progression, J. Invest. Dermatol., 2016, 136, 2140-2149.

6 B. A. Morgan, The dermal papilla: an instructive niche for epithelial stem and progenitor cells in development and regeneration of the hair follicle, Cold Spring Harbor Perspect. Med., 2014, 4, a015180.

7 J. S. Crabtree, E. J. Kilbourne, B. J. Peano, S. Chippari, T. Kenney, C. McNally, et al., A mouse model of androgenetic alopecia, Endocrinology, 2010, 151, 2373-2380.

8 J. I. Yoon, S. M. Al-Reza and S. C. Kang, Hair growth promoting effect of Ziziphus jujuba essential oil, Food Chem. Toxicol., 2010, 48, 1350-1354.

9 R. K. Roy, M. Thakur and V. K. Dixit, Hair growth promoting activity of Eclipta alba in male albino rats, Arch. Dermatol. Res., 2008, 300, 357-364.

10 B. Zhang, R. W. Zhang, X. Q. Yin, Z. Z. Lao, Z. Zhang, Q. G. Wu, L. W. Yu, X. P. Lai, Y. H. Wan and G. Li, Inhibitory activities of some traditional Chinese herbs against testosterone $5 \alpha$-reductase and effects of Cacumen platycladi on hair re-growth in testosterone-treated mice, $J$. Ethnopharmacol., 2016, 177, 1-9.

11 N. N. Zhang, D. K. Park and H. J. Park, Hair growthpromoting activity of hot water extract of Thuja orientalis, BMC Complementary Altern. Med., 2013, 13, 9-20.

12 S. R. Seo, G. Kang, J. W. Ha and J. C. Kim, In vivo hair growthpromoting efficacies of herbal extracts and their cubosomal suspensions, J. Ind. Eng. Chem., 2013, 19, 1331-1339.

13 B. A. Moharam, I. Jantan, J. Jalil and K. Shaari, Inhibitory effects of phylligenin and quebrachitol isolated from Mitrephora vulpina on platelet activating factor receptor binding and platelet aggregation, Molecules, 2010, 15, 7840-7848.

14 K. Kar, V. N. Puri, G. K. Patnaik, R. N. Sur, B. N. Dhawan, D. K. Kulshrestha and R. P. Rastogi, Spasmolytic constituents of Cedrus deodara (Roxb.) Loud: pharmacological evaluation of himachalol, J. Pharm. Sci., 1975, 64, 258-262.

15 Y. Yada, H. Sadachi, Y. Nagashima and T. Suzuki, Overseas survey of the effect of cedrol on the autonomic nervous system in three countries, J. Physiol. Anthropol., 2007, 26, 349-354.

16 D. Kagawa, H. Jokura, R. Ochiai, I. Tokimitsu and H. Tsubone, The sedative effects and mechanism of action of cedrol inhalation with behavioral pharmacological evaluation, Planta Med., 2003, 69, 637-641.

17 Y. C. Su, K. P. Hsu, E. I. Wang and C. L. Ho, Composition anticancer and antimicrobial activities in vitro of the heartwood essential oil of Cunninghamia lanceolata var. konishii from Taiwan, Nat. Prod. Commun., 2012, 7, 12451247.

18 I. Oh, W. Y. Yang, J. Park, S. Lee, W. Mar, K. B. Oh and J. Shin, In Vitro $\mathrm{Na}^{+} / \mathrm{K}^{+}$- ATPase inhibitory activity and antimicrobial activity of sesquiterpenes isolated from Thujopsis dolabrata, Arch. Pharmacal Res., 2011, 34, 21412147.

19 RIFM (Research Institute for Fragrance Materials Inc.), Report on human maximization studies, RIFM, Woodcliff Lake, NJ, USA, 1973b.

20 A. M. Kligman and W. Epstein, Updating the maximization test for identifying contact allergens, Contact Dermatitis, 1975, 1, 231-239. 
21 Y. Zhang, L. Han, S. S. Chen, L. Guan, F. Z. Qu and Y. Q. Zhao, Hair growth promoting activity of cedrol isolated from the leaves of Platycladus orientalis, Biomed. Pharmacother., 2016, 83, 641-647.

22 S. S. Chen, Y. Zhang, Q. L. Lu, Z. Lin and Y. Zhao, Preventive effects of cedrol against alopecia in cyclophosphamidetreated mice, Environ. Toxicol. Pharmacol., 2016, 46, 270-276.

23 S. P. Bhatia, D. McGinty, C. S. Letizia and A. M. Api, Fragrance material review on cedrol, Food Chem. Toxicol., 2008, 46, S100-S102.

24 N. Aggarwal, S. Goindi and R. Khurana, Formulation, characterization and evaluation of an optimized microemulsion formulation of griseofulvin for topical application, Colloids Surf., B, 2013, 105, 158-166.

25 J. M. Adams and S. Cory, The Bcl-2 protein family: arbiters of cell survival, Science, 1998, 281, 1322-1326.
26 Y. AI-Nuaimi, G. Baier, R. E. Watson, C. M. Chuong and R. Paus, The cycling hair follicle as an ideal systems biology research model, Exp. Dermatol., 2010, 19, 707-713.

27 S. Müller-Rover, B. Handjiski, C. van der Veen, S. Eichmüller, K. Foitzik, I. A. McKay, K. S. Stenn and R. Paus, A comprehensive guide for the accurate classification of murine hair follicles in distinct hair cycle stages, J. Invest. Dermatol., 2001, 117, 3-15.

28 H. B. Chase, Growth of the hair, Physiol. Rev., 1954, 34, 113126.

29 P. M. Plonka, D. Michalczyk, M. Popik, B. Handjiski, A. Slominski and R. Paus, Splenic eumelanin differs from hair eumelanin in C57BL/6 mice, Acta Biochim. Pol., 2005, 52, 433-441. 